\title{
Editors' Welcome
}

With far too many scholarly journals out there now, why launch yet another? Hurried readers may never recognize what THYMOS is about unless they get past the first word to what follows: Journal of Boyhood Studies. That may happen in quite a few cases at first, but we are convinced that once underway, THYMOS will take its place among the best interdisciplinary journals in English. Boys, we believe, have something to teach us about the body, sexuality, spirituality and the imagination and, for that reason, without wishing to be excessive, we want to emphasize our conviction that the subject matter of THYMOS - boys and boyhood - is central to everyone's self-understanding as a human being in what will very soon be a thoroughgoing global culture.

We have conceived of THYMOS as a journal that is dedicated, first and foremost, to helping us especially in the developed West clearly see a phenomenon that is by no means intuitively obvious - "the boy." In its pages we want to explore whether boyhood is unique to certain cultures or a given historical period, or whether it has fundamental ontological status. It may well turn out that boyhood is an intellectual artifact of European-American modernity, or it may be that boyhood is cross-culturally ubiquitous, for example, in relation to manhood. Here we have in mind David Gilmore's argument from an anthropological perspective for the near universality of manhood in Manhood in the Making. As for the ubiquity of boyhood, we must wait to see. We hope that the studies appearing in THYMOS will help us decide.

THYMOS is dedicated to "saving the phenomenon," as Aristotle said, that is, being true to what we call boyhood and its incarnations in those human specimens we in the West call boys. Following Kenneth Kidd, we favor reviving the term boyology as a more formal name for boyhood studies. Recently, Kidd has examined early $20^{\text {th }}$ century "boy work" in his Making American Boys: Boyology and the Feral Tale. The term "boyology" turned up in 1916, during World War I, as the title of a book on the biological and social development of boys written by a leader of the YMCA, Henry William Gibson. But what did Gibson and his predecessors, beginning in 1844 when the YMCA was founded, have in mind when writing about boys "that they may all be one"? This was the very year it just so happens, that the famous proverb originated: "All work and no play makes Jack a dull boy." But what was a boy then and what is he now? What is the provenance of boyhood in our cultural imagination and how does the phenomenon jibe, if at all, with how we see male human beings until pubarche and several years - perhaps as long as a decade-beyond? One thing is clear to us. In the West, boyhood has come to extend well past puberty. For that reason, the studies and

THYMOS: Journal of Boyhood Studies, Vol. 1, No. 1, Spring 2007, 3-5.

(C) 2007 by the Men's Studies Press, LLC. All rights reserved. http://mensstudies.com thy. $0101.3 / \$ 10.00$

DOI: $10.3149 /$ thy. 0101.3 
reflections published in THYMOS will encompass the years from early and middle childhood to the beginning of the male's third decade of life.

But who decides these matters, the end of infancy and the beginning of boyhood, and the end of boyhood and male adolescence? Further questions arise: Can we speak of boyhood unless we already have a notion of manhood with which to contrast it at its end? Is there a meaningful relationship between boyhood and girlhood? While all are children, are girls and boys analogous types? What does "the boy" signify? What does the phenomenon indicate? Is "the boy" the same everywhere? What purposes do boys serve in various cultures?

If we can confirm and describe the ontological status of the boy, we will then be in a position to begin to see what he is and what boyhood - "the state of being a boy; the time of life during which one is a boy"- means. The word boyhood seems to be the invention of Jonathan Swift almost exactly a century before the American association for "young men" was instituted. Swift himself makes a clear distinction between boyhood and manhood. Perhaps, then, we have an important clue about this "time of life" and the relation of boyhood to manhood. Or are we misled by a culturally well-circumscribed, singularly Western notion? In general, more and more of what we know suggests "the boy" is a fairly recent invention, so that a history of boyhood may well turn out to be brief (if not easy to write). Nonetheless, the importance of boyhood seems undeniable.

There are, of course, other candidates for the critical player in the emergence of a worldwide experience of being-human, so we must try to see where boys are positioned in relation to the sexes, genders, and age groups that have been distinguished in the West. Our conviction remains, however, that the part played by the boy will turn out to have been crucial in the origin of the global ethos, which doubtless will be less and less dominated by easy binaries. At the very least, to decide about our claim, the evidence of biology, anthropology, developmental psychology, history, and literature must all come to terms with "the boy."

In an effort to see what we call the boy, contributors to THYMOS will examine many related topics: depictions of boyhood in art and photography, rituals and practices that focus on the end of boyhood in the many hundreds of cultures described by (mostly Western) anthropologists, psychological and sociological accounts of the development and significance of the experience of being a boy, and how our way of speaking, how language has delineated and circumscribed what we have come to call boys.

The audience of THYMOS is meant to include teachers and scholars, those who carry out empirical research, field workers, health care practitioners, and public policy makers. Its mission is to initiate dialogue among perspectives ranging from medical and legal practice, curriculum design and ethnography, to philosophical and personal reflections on boyhood and being-a-boy. The topics of THYMOS will include boys and schooling, parenting (especially the father-son relation and the effects of the missing father), and boyhood subcultures and sexualities. THYMOS will address the physical, emotional and sexual abuse of boys, the portrayal of boys in art, literature and the media, boys and sport, and the folklore and myths of boyhood. 
We are committed to being culturally comprehensive and inclusive, and by no means limited to considerations of Western boyhood - unless, that is, boyhood turns out to be an artifact of Western cultures.

We invite readers of THYMOS to visit and follow the development of http://www. boyhoodstudies.com, the online project that spawned our journal. On the site you will find an ever-expanding archive of bibliographic and other sources on boyhood. The bibliography of published material already includes more than 2,300 items. The visitor will also find links to related projects, conferences, and other scholarly work in the fields that encompass the phenomenon we wish to bring into view.

During many long conversations, the two principal editors considered what to call the journal and how to represent its topic metaphorically and visually. The evanescent nature of boyhood suggested that mysterious organ of the body close to the heart, the thymus. The name has rich associations to qualities of the human spirit that are especially lively in boys. Hence the name THYMOS with its richly nuanced references to Homer and Greek literature and philosophy, to the astral, animal soul, and the Pascalian "heart," and to the spiritedness of life and the human imagination. Like boyhood, thymos is sometimes full of righteous anger, even rage and frenzy. Also like boyhood, the organ in our bodies called the thymus will have largely vanished at the advent of adulthood.

For an image of boyhood, we chose for our signature cover art the figure of Ganymede, specifically as represented in the magnificent marble sculpture "Ganymede Waters Zeus as an Eagle" (1817) by the Danish sculptor Bertel Thorwaldsen. It is an image, we believe, that neatly suggests the foreground position of the boy in relation to manhood, fathers, and all of nature, especially human nature.

Our editorial board consists of thirty-seven distinguished scholars, twenty-two men and fifteen women, representing nine countries and a range of disciplines, from medicine and anthropology to psychology, psychoanalysis, sociology and pedagogy. We are grateful for their support of this venture.

And so we offer the inaugural issue of THYMOS with the expectation that it will be the first in a series of collections of essays and studies that will help us see this remarkable phenomenon, the boy.

Miles Groth, PhD, Editor (USA)

Diederik F. Janssen, MD, Managing Editor (The Netherlands) 